\title{
Neutronographic Fabric Analysis of Quartz in Naturally Deformed Gneiss
}

\author{
L. P. DRECHSLER, K. FELDMANN, A. FRISCHBUTTER $\dagger$ and \\ K. WALTHER \\ Laboratory of Neutron Physics, Joint Institute for Nuclear Research Dubna, \\ Head Post Office Box 79, Moscow, USSR \\ + Central Institute of the Physics of the Earth, Academy of Sciences of GDR, \\ DDR-1500 Potsdam, GDR
}

(Received July 3, 1987; in final form August 20, 1987)

Dedicated to the memory of Prof. Dr. Günter Wassermann

The crystalline preferred orientations of quartz grains in pencil gneiss from the Erzgebirge (southern GDR) are studied by means of neutron time-of-flight diffraction. A single component texture has been found where the trigonal axes are parallel to the tectonic $a$-direction. In the quartz $c$-axis pole figure strong maxima at tectonic $\pm a$ are connected by a girdle of weaker intensity being not found in $U$-stage measurements. From the comparison with experimentally deformed quartzites and model calculations the approximate formation conditions of the given pencil gneiss could be deduced.

KEY WORDS: Gneiss, quartz, fabric analysis, ODF analysis, neutron diffraction, time of flight method.

\section{INTRODUCTION}

The orientation distribution of crystallites in tectonites contains valuable information on deformation process which have taken place in the Earth's crust. Comparing the preferred orientations in naturally deformed rocks with the results from experimentally 
deformed material and computer simulations of deformation process, the data can be used to estimate the regime of temperature, pressure, stress and strain as well as the preferred operating mechanisms of deformation which were active in the investigated matter. Therefore, important information for petrofabric analysis can be expected from the accurate and complete description of the relation between crystal and specimen orientations. In this sense, the determination of the orientation distribution function (ODF) is favoured in comparison with fabric diagram measurements like those known in structural geology. The reproduction of the ODF from pole figure data, determined by neutron or X-ray diffraction, is a very straightforward way to calculate this function.

In the last years some preferred orientation studies carried out on this base in different geological materials have been reported (e.g. Bunge and Wenk, 1977; Bankwitz et al., 1984; Wagner et al., 1982).

In this paper the partial texture of quartz in orthogneisses from the middle Erzgebirge (GDR) is studied. The sample has been taken from the very crest of a recumbent fold structure. All pole figure measurements were carried out using neutron time-of-flight (TOF) diffraction at the pulsed reactor IBR-2 in Dubna (Feldmann, 1986). This method is well suited for the investigation of low symmetric crystal systems like quartz because of simultaneous measuring of several pole figures. Furthermore, this technique allows one to study natural multiphase aggregates with sufficient accuracy (Feldmann et al., 1986). The ODF reproduction from experimental pole figures and the determination of recalculated and inverse pole figures have been done by means of spherical harmonics analysis (Bunge, 1982; Matthies, 1982).

\section{GEOLOGICAL BACKGROUND AND SPECIMEN CHARACTERIZATION}

In the present paper the fabric of an orthogneiss is investigated from an exposed range within a folded complex being typical for the upper part of the Earth's crust $(5 \mathrm{~km}$ depth). From the structural geological point of view this deformation consists in an intensely asymmetric folding of a \pm parallel system of planes (crystalline 
schistosity $\left.s k_{1}\right)$. As a result of this folding a younger crystalline schistosity $\left(s k_{2}\right)$ is formed nearly parallel to the orientation of the axial plane of the folds connected with intimate crenellation of the older schistosity $\left(s k_{1}\right)$ near the crest of the folds having pencil structures ( $b$-tectonites) in the very crest of the folds (see Figure 1).

Together with increasing isoclinal structure of the folds the orientation of the younger crystalline schistosity $\left(s k_{2}\right)$ approaches more and more an axial position. So it becomes obvious, that on the limbs of the fold the older and newly formed crystalline schistosites are approximately parallel. Near to the crest of the fold the intersection angle of both foliations is increasing and reaches $90^{\circ}$ in the very crest. The crest is, furthermore, characterized by the morphological dominance of the $s k_{2}$-plane as well as by stretching in $b=x$ (pencil-structure) combined with rotation around $b=x$-axis.

Such deformation process is in a wide range independent of different types of parent rocks, their chemical composition and regional geological position. According to critical minerals in the present case the deformed system of planes $\left(s k_{1}\right)$ corresponds to a crystalline schistosity formed by regional metamorphism under the conditions of the amphibolite-facies $\left(p>4,5 \mathrm{kbar}, T>400-500^{\circ} \mathrm{C}\right)$. Nearly the same or even somewhat lower metamorphic conditions are to be taken into consideration due to the development of the younger crystalline schistosity $\left(s k_{2}\right)$. These data are derived from the occurence of younger biotite following the $s k_{2}$-planes.

The studied sample is a pencil gneiss from the very crest of an

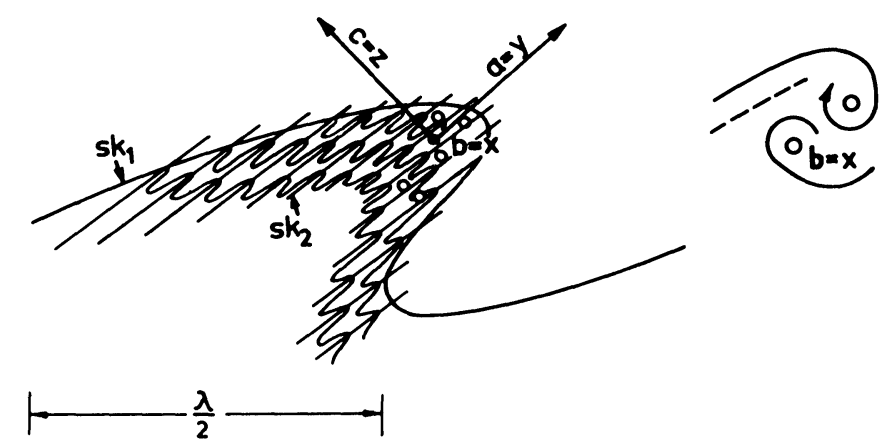

Figure 1 Structural-geological position of the studied sample. The relation between petrofabric coordinate system $a b c$ and sample coordinate system $x y z$ is shown. 
asymmetric recumbent fold with a half wave length of about $1 \mathrm{~km}$ (Figure 1). It has been taken in a quarry $1.5 \mathrm{~km}$ south of Joehstadt at the boundary to Czechoslovakia. The geological unit is an orthogneiss complex ("redgneiss") of the Erzgebirge-anticlinorium named "Reitzenhainer Rotgneisstruktur" (Frischbutter, 1985). The sample is cut as a plate with about $1 \mathrm{~cm}$ thickness perpendicular to the $c=z$ axis and an area of about $15 \times 20 \mathrm{~cm}^{2}$ in the $a b=x y$ plane. By means of X-ray phase analysis proved by microscope modal analysis the main minerals are determined contributing to the pencil-gneiss specimen under investigation: quartz $35 \%$, plagioclase $35 \%$, K-feldspar $15 \%$ muscotive $10 \%$, biotite $5 \%$.

\section{EXPERIMENTS}

The present fabric analysis of quartz in pencil-gneiss has been done at the pulsed reactor IBR-2 in Dubna using neutron time-of-flight (TOF) diffraction. The method is similar to the energy-dispersive $\mathrm{X}$-ray technique. It is characterized by a simultaneous recording of all nonforbidden Bragg reflections in one diffraction pattern at constant scattering geometry. This means all pole figures under investigation are measured at the same time by only one scan of the texture goniometer.

The experiments were carried out at the spectrometer NSWR (Ananiev et al., 1984). Some important parameters of the equipment are:

total flight path: $\quad L_{1}+L_{2}=34.2 \mathrm{~m}$

detector positions: $\left.\begin{array}{l}2 \theta_{1}=80^{\circ} \\ 2 \theta_{2}=100^{\circ}\end{array}\right\} \quad\left\{\begin{array}{l}\text { transmission } \\ \text { geometry }\end{array}\right.$

beam diameter $\quad D=5 \mathrm{~cm}$

$$
\left.\begin{array}{l}
2 \theta_{1}=140^{\circ} \\
2 \theta_{2}=100^{\circ}
\end{array}\right\} \quad\left\{\begin{array}{l}
\text { reflection } \\
\text { geometry }
\end{array}\right.
$$

In Figure 2 the TOF diffraction pattern at $2 \theta=80^{\circ}$ is shown, which is normalized to constant neutron flux. The channel numbers are proportional to the neutron wavelength. Using two detectors in transmission and reflection geometry as well, complete pole figures could be determined by rotating the goniometer around its normal situated in the horizontal scattering plane (azimuth angle $\psi$ ), and 


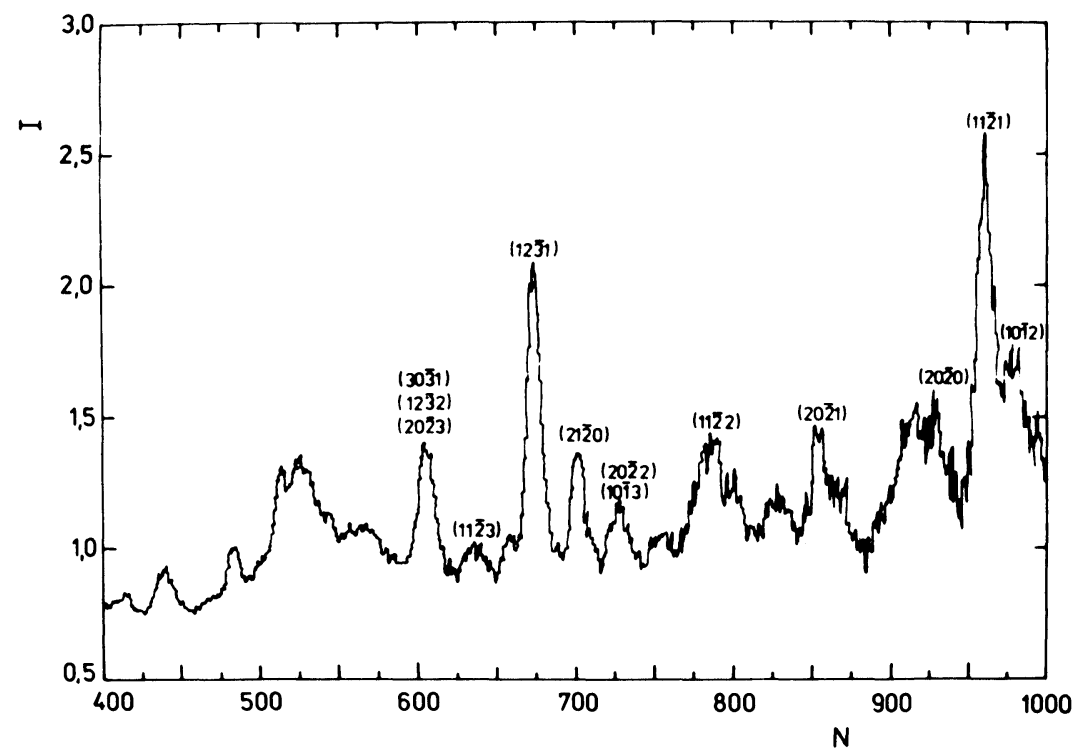

Figure 2 TOF diffraction pattern of pencil gneiss $\left(2 \theta=80^{\circ}\right)$.

around the vertical axis (tilt angle $\vartheta$ ). The pole figures were measured in constant- $\vartheta$-circles (see Figure 3 ). The steps are equidistant $\Delta \vartheta=10^{\circ}$. The $\Delta \psi$-steps vary in dependence on $\vartheta$ (see the table). The pole figure ranges for transmission and reflection geometry and the results from different detectors have been compared by means of special calibration circles.

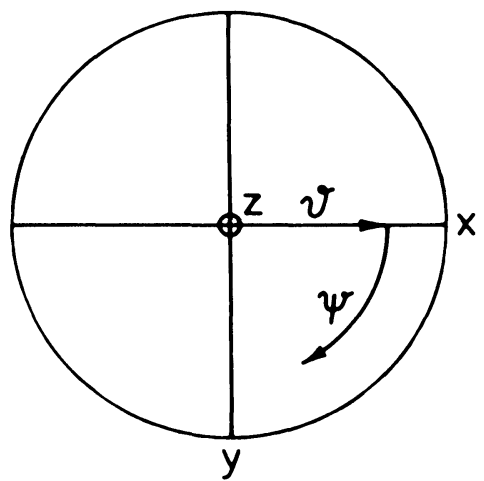

Figure 3 Pole figure angles. 
Table 1 Dependence of angle steps $\Delta \psi$ on tilt angle $\vartheta$

\begin{tabular}{ccccccccccc}
\hline$\vartheta$ & $0^{\circ}$ & $10^{\circ}$ & $20^{\circ}$ & $30^{\circ}$ & $40^{\circ}$ & $50^{\circ}$ & $60^{\circ}$ & $70^{\circ}$ & $80^{\circ}$ & $90^{\circ}$ \\
\hline$\Delta \psi$ & $36^{\circ}$ & $30^{\circ}$ & $36^{\circ}$ & $30^{\circ}$ & $24^{\circ}$ & $20^{\circ}$ & $18^{\circ}$ & $15^{\circ}$ & $10^{\circ}$ & $10^{\circ}$ \\
\hline
\end{tabular}

\section{POLE FIGURE DETERMINATION AND DATA HANDLING}

The values of pole figures are proportional to the intensity of their Bragg reflection at the corresponding specimen position. These intensities were determined from TOF spectra by means of a computer fit. The quartz phase of the gneiss has only be considered. Because of several other components in the material having low lattice symmetries, the diffraction patterns contain a large amount of peaks. Therefore, problems in the fit procedure arise due to overlappings and coincidences of reflections:

- In regions consisting in dense sequences of reflections it may be impossible to find reliable points for background correction. Therefore, corresponding errors may occur. They are reflected in the pole figure normalization and simulate incorrect sharpness of texture.

- Narrowly overlapped or coincident reflections cannot be separated by means of the fit. As a result, the determined intensities are expected to include influences from other phases. An approximate phase analysis (components of more than 5 percents) can be used to simulate the TOF spectra of single phases and to select weakly "contaminated" peaks for further consideration.

In the present fabric analysis those quartz reflections have been picked up where the influence of other phases was lower than $30 \%$. For the understanding of weak textures of all components the arising errors are supposed to be small. Accurate and mutually consistent pole figures are the base for the mathematical texture analysis. Efforts have been made to check the quality of pole figures and to correct them for the errors discussed above. The applied criteria and methods are outlined in more detail by Feldmann et al. (1986).

The mathematical texture analysis up to the ODF calculation has been carried out using the well known series expansion method (Bunge, 1982) up to $\iota=14$ for even $\iota$ only. The Euler angles $\alpha, \beta$, $\gamma$ are used with respect to the notation of Matthies (1982). In the 
applied formalism real and imaginary terms were considered separately. In the trigonal system the lattice planes (hkil) and (khil) are not symmetrically equivalent although they have the same lattice spacing and are, therefore, coincident in powder diffraction patterns. Consequently, pole figures of this type cannot be measured separately. They are taken into account with respect to the method outlined by Bunge and Wenk (1977).

\section{RESULTS}

From time-of-flight diffraction patterns of the pencil gneiss specimen 6 pole figures have been determined and selected for further consideration according to the check mentioned in the previous paragraph. The specimen coordinate system has been chosen in a way, that the quartz pencils in the gneiss representing the direction of the tectonic $b$-axis are parallel to the sample $x$-axis. An approximately orthorhombic symmetry of pole figures can be attained after the rotation of the sample coordinate system around the $z$-axis for about 20 degrees and around the $y$-axis for about 8 degrees. The rotation around the $z$-axis is carried out for the experimental pole figures in Figure 4, i.e. they are denoted by the actually used sample coordinate system $x y z$. The deviation between the tectonic and primary specimen coordinate system can be explained by the uncertainties at sample preparation and at sample calibration in goniometer. The initial set of pole figures has been recalculated from $C_{t}^{\mu \nu}$-coefficients (Figure 5). The differences in texture components are less than $10 \%$ of the pole density.

Furthermore, the pole figures of some important morphologic forms have been recalculated (Figure 6). The pole figure of the basal plane $\{0001\}$ shows an intense maximum at $y=a$ and a tendency to a weak girdle from $y=a$ to $z=c$. Moreover, it is compared with a fabric diagram of quartz axes determined by U-stage technique (200 axes in an $a$-c-section). The principal coincidence of both results is quite satisfactory. In the optically determined fabric diagram no tendency to the girdle formation can be found. This lack may be explained by the consideration of quartz grains from the pencils only. In the diffraction experiment the quartz grains of the matrix having very small grain sizes are 

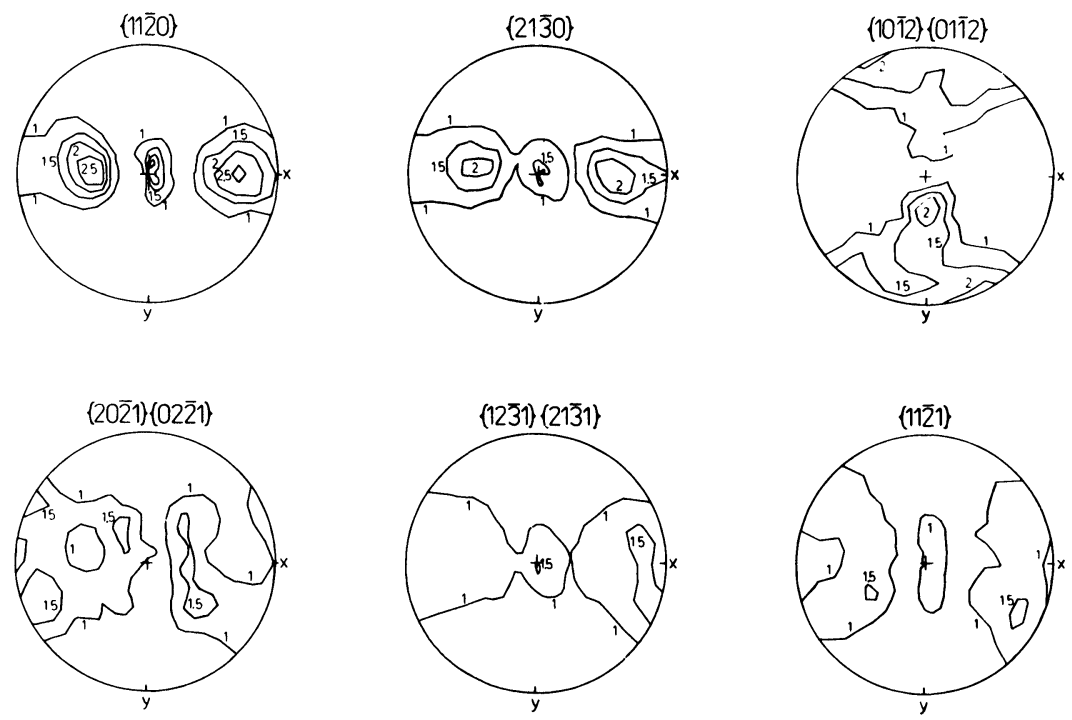

Figure 4 Experimental pole figures.
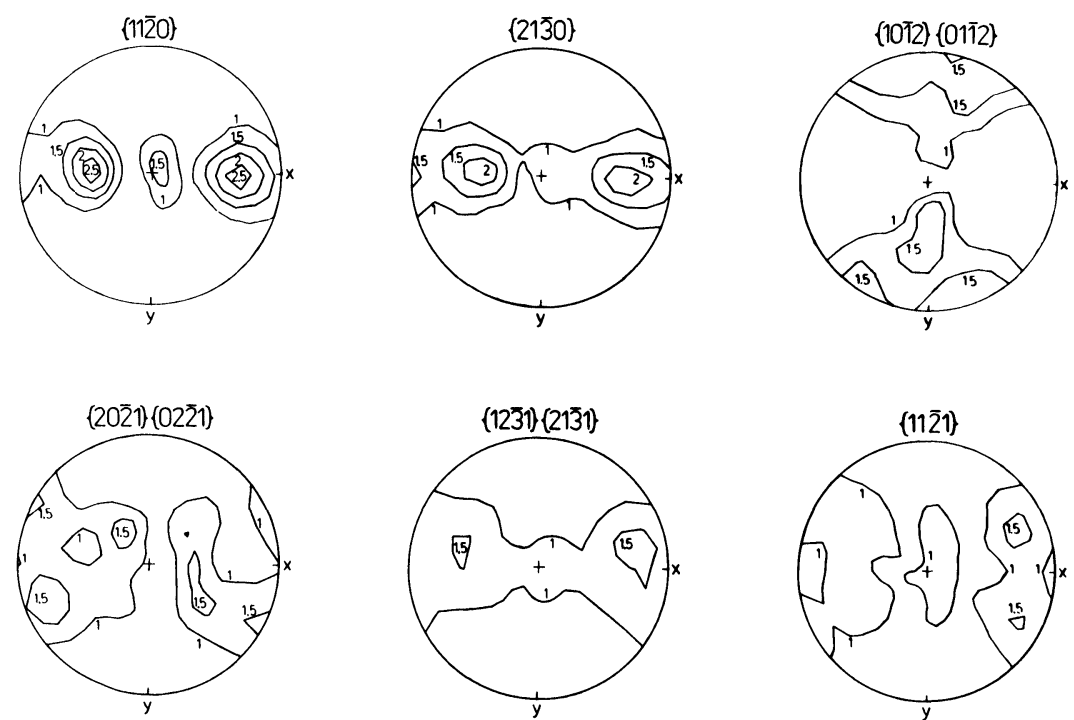

Figure 5 Recalculated pole figures (initial set). 

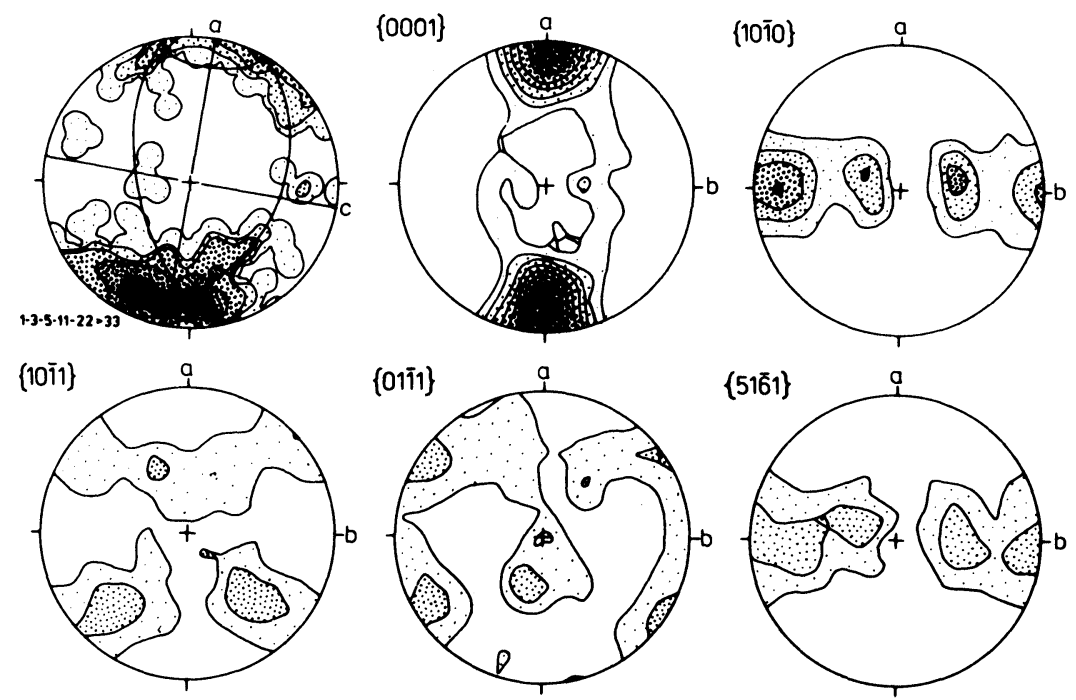

Figure 6 Quartz c-axes diagram (200 axes) (left on the top) and recalculated pole figures of morphological forms.
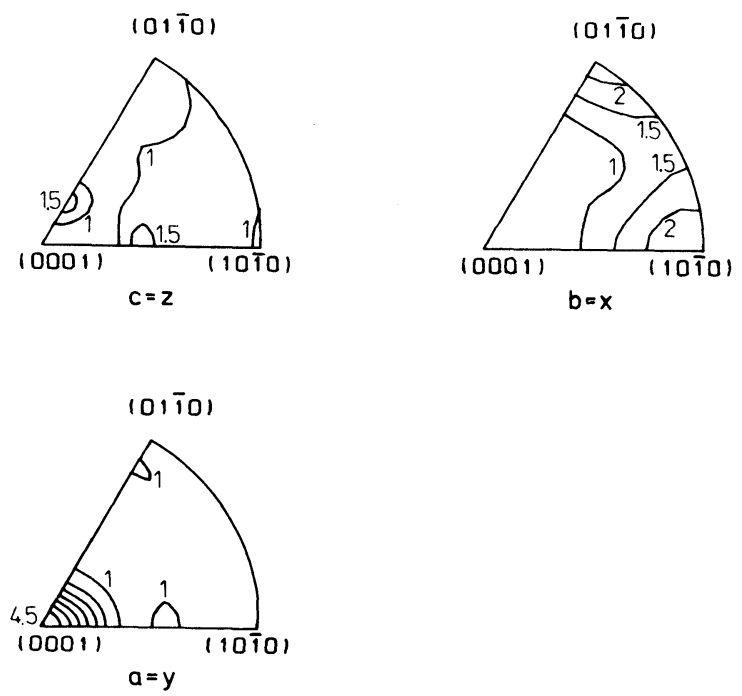

Figure 7 Inverse pole figures of the specimen coordinate axes. 
contributing to the pole figures also. On the other hand the separation of the maximum at $a=y$ into two in the fabric diagram having an angle distance of about 20 degrees is not observed in the $\{0001\}$ pole figure. It is supposed to be smoothed out in consequence of the relatively low series expansion degree and the choosen point density on the experimental pole figures.

Figure 7 shows the inverse pole figures for the specimen coordinate axes. Beside the strong maximum at (0001) in the $y$-direction no other significant texture component is observed. The existence of only one marked component is confirmed by the ODF in Figure 8 . The two maxima at $\pm y$ in the $\{0001\}$ pole figure are reflected by high intensities in the ODF at $\beta \approx 90^{\circ}, \alpha_{1}=90^{\circ}$ and $\alpha_{2}=270^{\circ}$, respectively. Figure 9 represents the skeleton lines of

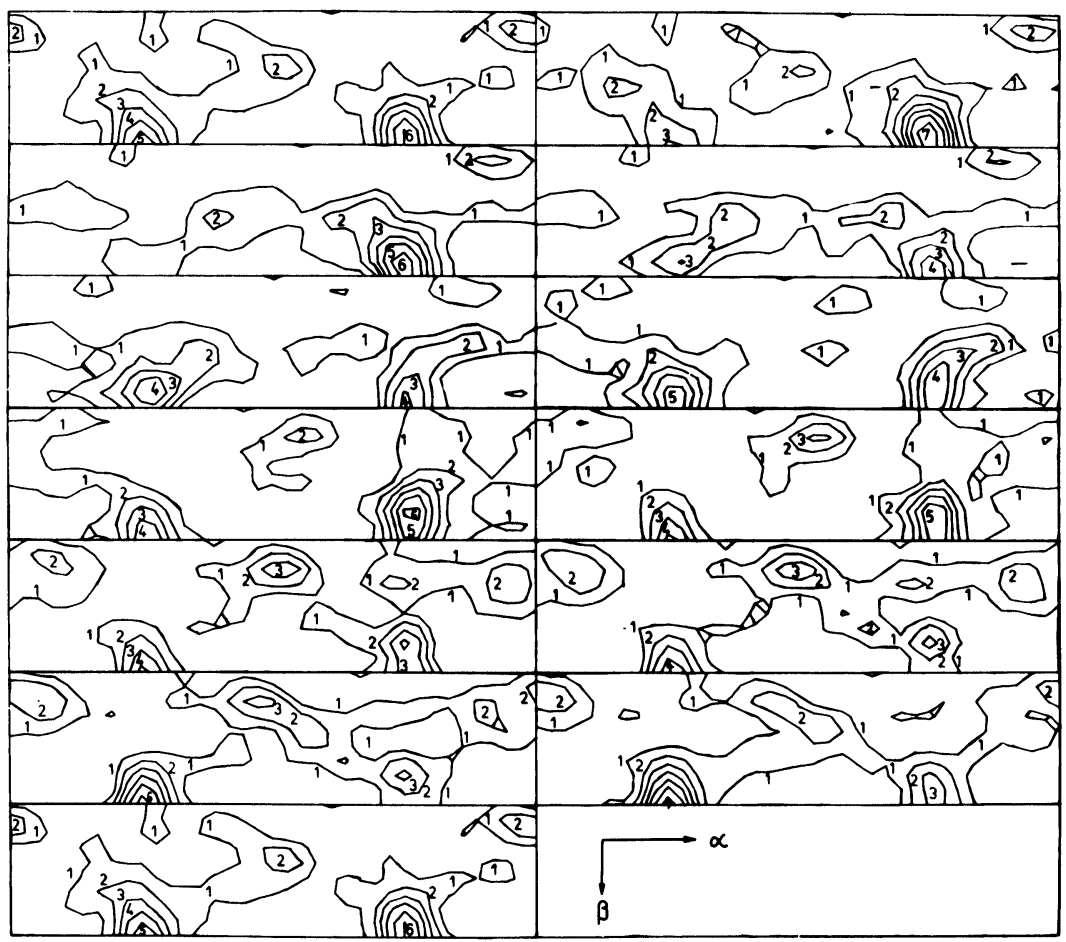

Figure 8 Quartz ODF of pencil gneiss represented for Euler angle ranges $0 \leq \alpha \leq 360^{\circ}, 0 \leq \beta \leq 90^{\circ}$ in $\gamma=$ const. cuts $\left(\gamma\right.$ steps are 10 degrees from 0 to $120^{\circ}$ ). 

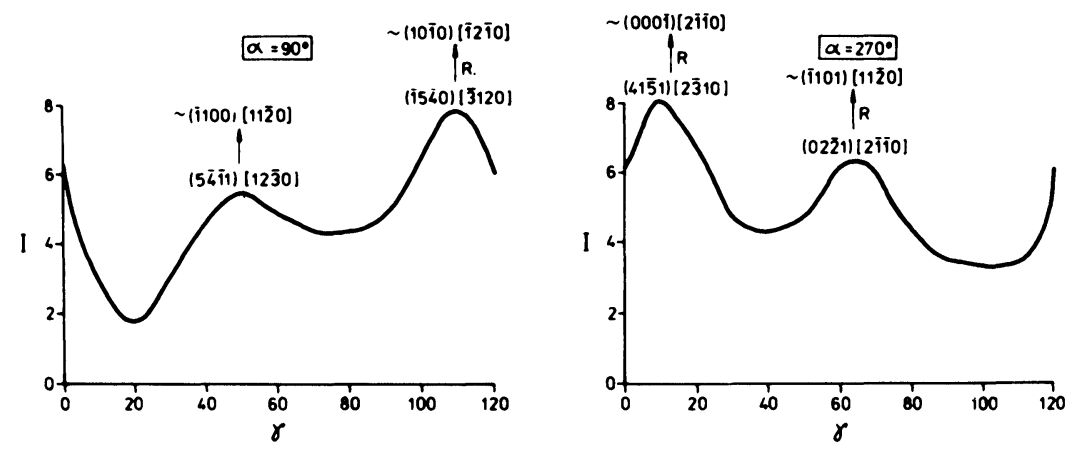

Figure 9 Skeleton lines of ODF maxima in dependence on $\gamma$.

both components in dependence on Euler angle $\gamma$. Each line shows two maxima having a distance of $60^{\circ}$. The skeleton lines are drawn for the maximum values of the corresponding ODF component even if $\beta$ tends to lower angles, especially in the neighbourhood of $\gamma=60^{\circ}$. The fluctuations of $\beta$ are explained by the incomplete orthorhombic symmetry of pole figures.

\section{INTERPRETATION}

The fabric type of the quartz phase in the pencil gneiss under investigation corresponds to the maximum I-preferred orientation of Sander (1970) combined with the tendency to an ac-girdle formation. Hofmann (1975) describes this kind of preferred orientations in his hierarchy of the evolution of the partial fabric of quartz in the Erzgebirge anticlinorium to be characteristical for the upper crust regions. According to Nicholas and Poirier (1976) the basal slip with the accompanying external rotations of $c$ toward $\delta_{1}$ leads to the $c$-axes maximum parallel to $\delta_{1}$ for temperatures below $800^{\circ} \mathrm{C}$ and strain rates $\dot{\varepsilon}=10^{-5} \mathrm{sec}^{-1}$ or other equivalent $(T, \dot{\varepsilon})$ values from Figure 10. In this region of the diagram plastic flow is operating without any recrystallization. The formation of girdle fabrics is explained by combined operation of basal and prismatic slip, where increasing influence of prismatic slip increases the opening angle of the girdle. 


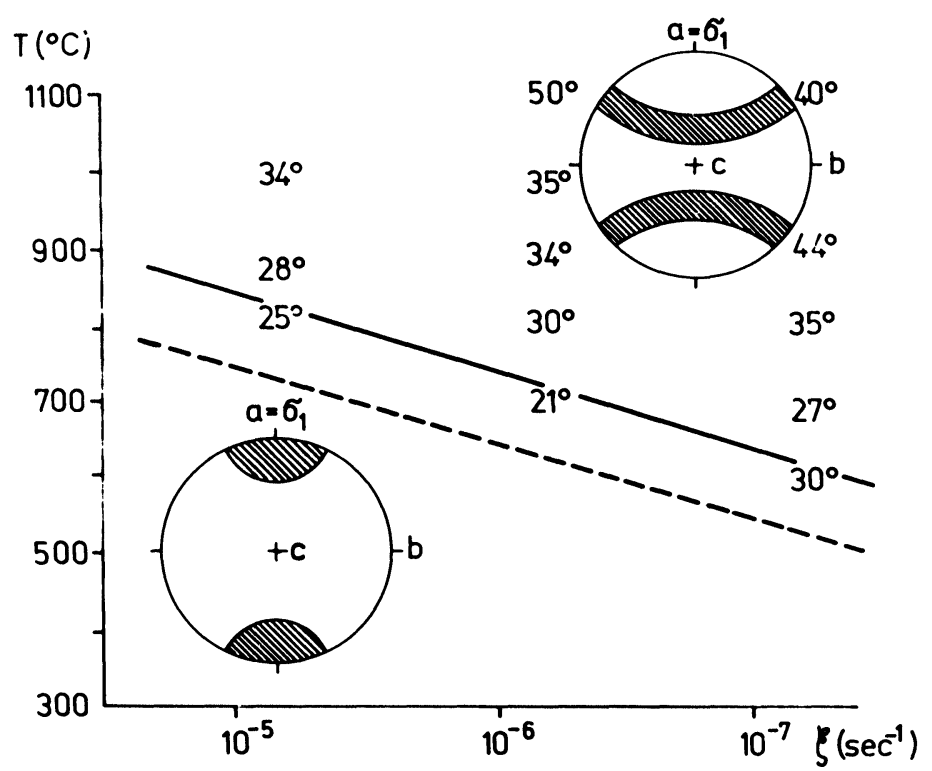

Figure 10 Variation of the preferred orientation of quartz $c$-axes with temperature and strain rate in quartzites. The numbers in parentheses indicate the average opening half-angle of the girdle.

The comparison of the determined fabric type with experimentally deformed quartzites refers to deformation conditions at relatively low temperatures $\left(<500^{\circ} \mathrm{C}\right)$, but higher strain rates $\left(\dot{\varepsilon} \leqslant 10^{-4} \sec ^{-1}\right)$ (Wenk, 1985).

According to Taylor-Bishop-Hill computer simulations performed by Lister and Hobbs (1980) the investigated texture corresponds to the "model quartzite $A$ " in the range between axial extension and flattening, where the dominating slip system is (0001) [a] (see Figure 11).

Finally, the important influence of the water content in quartz on its deformation behaviour has to be mentioned. Nicholas and Poirier (1976) have reported that a synthetic quartz crystal containing water molecules $\left(8.8 \times 10^{-3} \mathrm{H} / \mathrm{Si}\right)$ could be deformed above a critical temperature of $380^{\circ} \mathrm{C}$ under stresses by 10 to 20 times lower than a natural "dry" crystal. This hydrolytic weakening is attributed to the enhanced mobility of dislocations by hydrolysis of the strong covalent $\mathrm{Si}-\mathrm{O}$ bonds. 


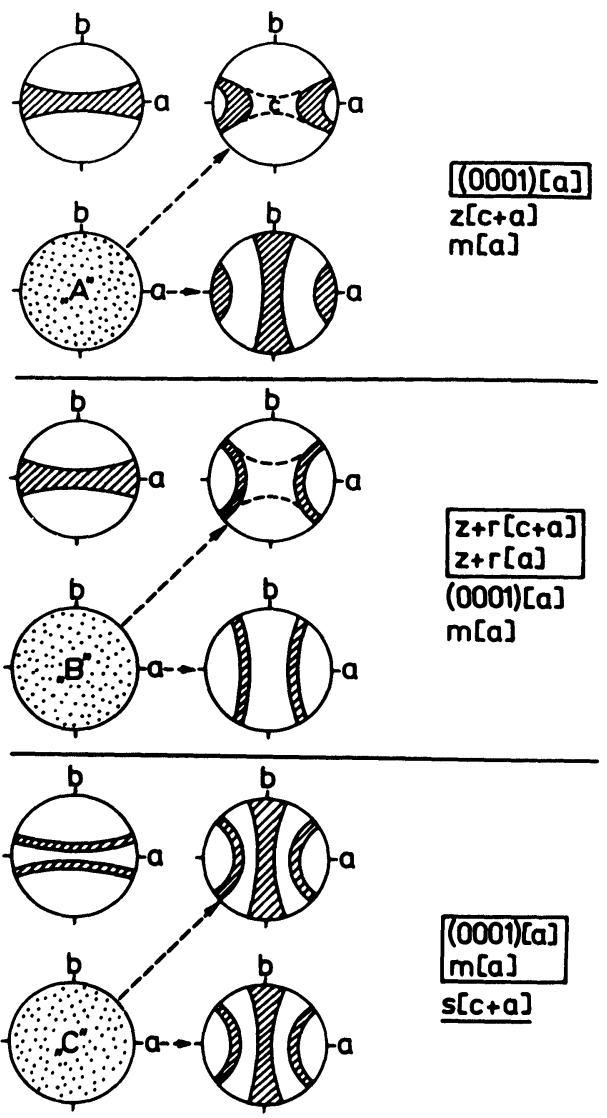

Figure 11 Results of Taylor simulations for three different models characterized by the noted slip systems which were assumed to be active in the deformation process (Lister and Hobbs, 1980). The vertical direction denotes axial extension, the horizontal one characterizes axial shortening and in the diagonale flattening takes place.

\section{References}

Ananiev, B. N., Betzl, M., Boede, W., Walther, K., Voronov, B. I., Goremychkin, E. A., Drechsler, L. P., Reichel, P., Urban, S., Feldmann, K., Fuentes, L. and Hoppe, U. (1984) JINR Communication P14-84-827 Dubna.

Bankwitz, P., Betzl, M., Drechsler, L. P., Feldmann, K., Fuentes, L., Kaempf, H., Matthies, S. and Walther, K. (1984) Proc. VII Int. Conf. on Textures of Materials (ICOTOM 7) Noordwijkerhout, pp. 753-758. 
Bunge, H. J. (1982). Texture Analysis in Materials Science, Mathematical Methods, London, Butterworth.

Bunge, H. J. and Wenk, H. R. (1977) Tectonophysics 40, 257-285.

Feldmann, K. (1986) Proc. Workshop on Experimental Techniques of Texture Analysis. Ed. H. J. Bunge, Oberursel DGM Informationsgesellschaft, pp. 253-263.

Feldmann, K., Fuentes, L., Walther, K. (1986) JINR Preprint E14-86-360, Dubna.

Frischbutter, A. (1985) Freib. Forsch. H. C390, 29-44.

Hofmann, J. (1975) Z. geol. Wiss. 3, 333-361.

Lister, G. S. and Hobbs, B. E. (1980) J. Struct. Geol. 2, 355-370.

Matthies, S. (1982) ZfK-Preprint ZfK-480, Rossendorf.

Nicholas, A. and Poirier, J. P. (1976) Crystalline Plasticity and Solid State Flow in Metamorphic Rocks, London, John Wiley and Sons.

Sander, B. (1970) An Introduction to the Study of Fabrics in Geological Bodies, Oxford, Pergamon Press.

Wagner, F., Wenk, H. R., Kern, H., Van Houtte, P. and Esling, C. (1982) Contrib. Mineral Petrol 80, 132-139.

Wenk, H. R. (1985) Preferred Orientation in Deformed Metals and Rocks: An Introduction to Modern Texture Analysis, Orlando, Academic Press. 